\title{
TÜRK MEVZUATININ ONAYLANAN ULUSLARARASI ANTLAŞMALAR ÍLE UYUMLAŞTIRILMASI SORUNU
}

Dos. Dr. Serap AKIPEK*

Günümüzde, özellikle, taraf olduğumư Avrupa Insan Hakları Sözleşmesi ve ILO Sözleşmeleri gibi dikkat çeken ömekler söz. konusu olduğunda bariz biçimde ortaya çıkan Türk mevzuatı ile Türkiye'nin onayladığı uluslararası antlaşmalar arasındaki kopuklık ve uyumsuzluğgun yarattı̆ğ sorunlar, olaylarmn güncelliğini yitirmesiyle birlikte, yeniden ait olduğu köșeye, bir dahaki sefere kadar unutulmak üzere itilmektedir.

1961 Anayasası'nın 65. maddesinin aynen benimsendiği 1982 Anayasasi'nin 90. maddesit, uluslararası antlaşmaların onayJanmasında izlenecek usulün temel çerçevesini belirlemekte ve son fikrasında da usulüne uygun olarak yürürlïğe konmuş ulustararası antlaşımaların kanun niteliğini kazanacağın ifade etmektedir. Somutlașırıldığında, Resmi Gazete'de yayımlanma şartı getirilen ant-

i: A.Ü. Hukuk Fakiiltesi Ögretim Üyesi.

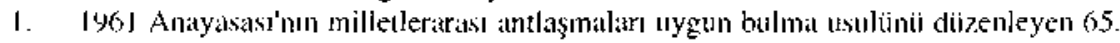
ic 97. Inaddeleri. 1982 Amayasass'nda 90) ve 104. madde metinlerinde "/96/ mer-

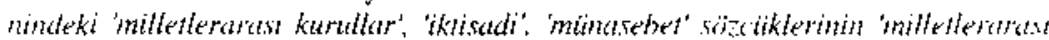

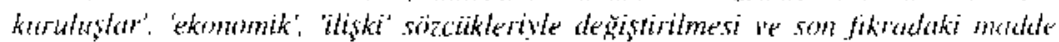

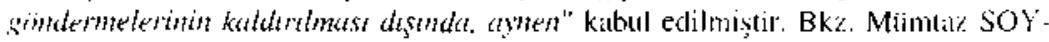

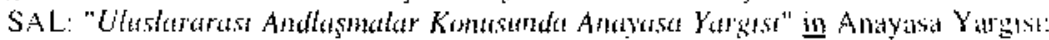
Anayasa Mahkemesi'nin 35. Kurulus Yıldönümif Nedeniyle Dïzenlenco Somporyunda Sunulan Bildiriler. Ankara, 1997, s. 175.

2. "Usatine göre yïrürtüge kmulmus milletlerardse andlasmalar kantm häkmändedi".

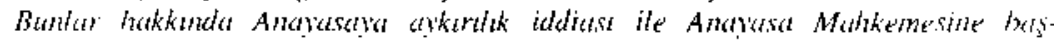
vitutemaz" Bkz. T.C. Antyasasi, m. 90/V. 
laşma türleri bakmmutan, bir Bakanlar Kurulu Kararmanesi ckinke. amlaşmamm akdedildiğ orijinal dillerden biri ile türkşe co-

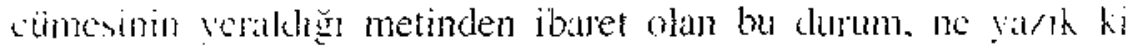
simcliys hialar bu belimemenin ölesine geçememjştir.

Bir dev letin uluskararası bir antlaşmalya tarafo olmass kendi rl/a.s diktrilinde gerçekleşen bir siireci jate eder. Kusaca hiç hir kes. let bir antlașmaya taraf olmak yöntinde torlamamayalcis̆ gibi. bijyle hì ilişki tçine giren süjenin. taraf olacağı antlaşmann ken. disme ne githi vatalar sağlayacağ ve ne gibi artular getirecegi hu-

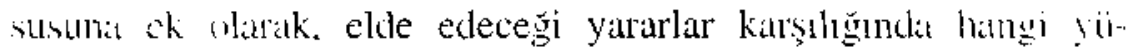
kimmlillikleri, borçlart üstleneceğgi, hangi tür yetki devirlerinde hulunatcag konukann irdeleyip, bunlarun dengelenmesi halink ant-

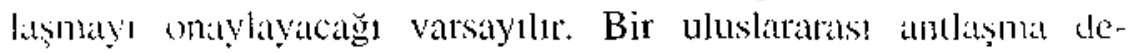
šerlenditilitken, taraf olmayl duişünen devletin ak!il vo pasil ha-

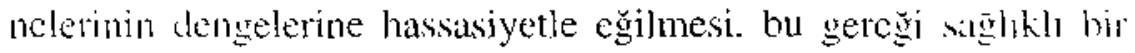
biçimk verine «etirebilmek için de antlaşma metninin hassisiyetle degerlendirimesi gerekecektir.

Bir uhulararass antlaşmaya, temelde uluslararas plattombat prestij ka/anmak, onaylayan diğer devletler kervanına kattlmak

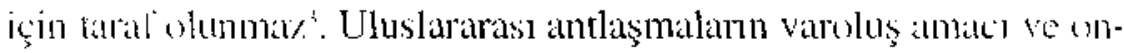
lata àkitlerince uyulmasindaki mantık, bu kadar anlamsiz bir amatca

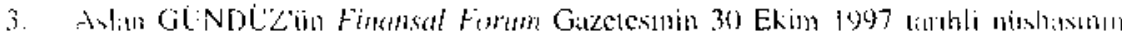

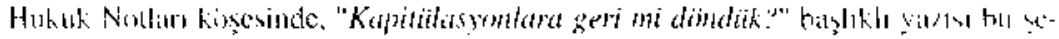

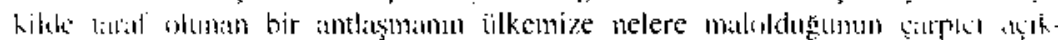

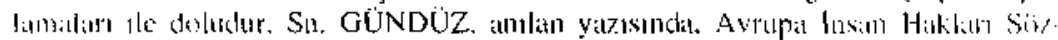

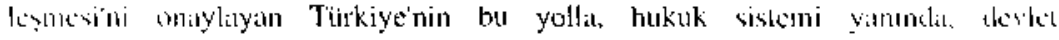

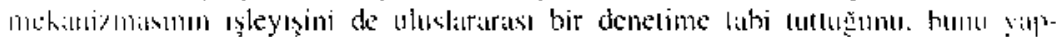

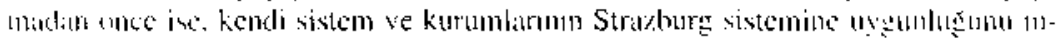

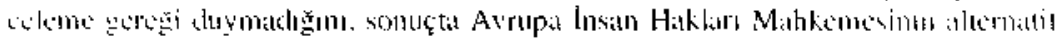

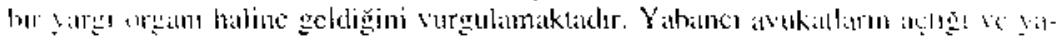

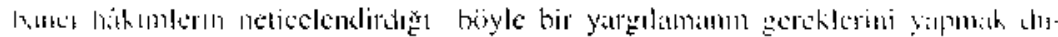

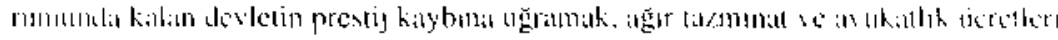
islandeh

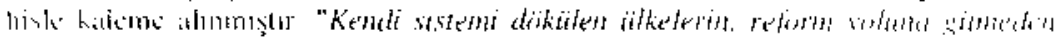

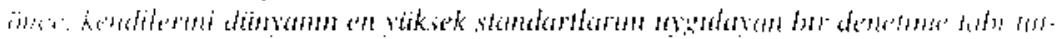

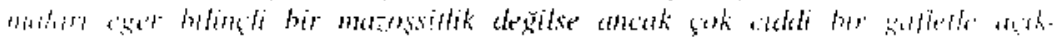

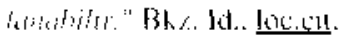


indirgeneme . Taraf olan devletlerin onay yönündeki açık nŁaların içeren. günümuizün her alandaki gelişmelerine en iyi biçinde yetişip atyak uydurabilen antlaşmalar, haiz oldukları bu özellikler silyesinde uluslararası hukukun diğer bir kaynağı uluslararası örf ve âđlet hukuku kurallartna nazaran bariz bir iistünlük taşırłat". Hiç kuşkusuz antlaşmalar aracılığıyla uluslararası alanda ulaşılmak istenen hedef, kural olarak karşılıklılık temelinde ortak hedeflere varmak, bunu da ortak ölçïtler, birörnek kurallar. tektip uygulamalar aracılığıyla başarmaktırs. Taraf olan devletler bakımından, antlaşmanın uygulama alanında en azmodan asgari bir ölçütü - stan-

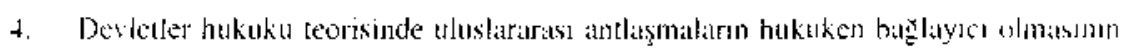

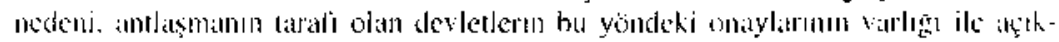

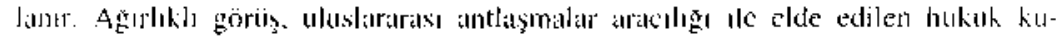
ralliarm, Devletler hukukunun diger kalynaklatr arasinda en ijste yerlestirmektur.

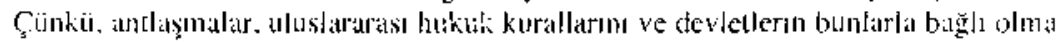

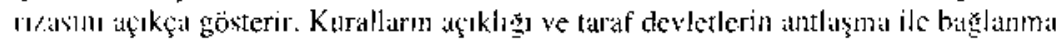

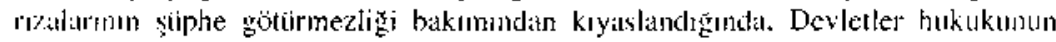

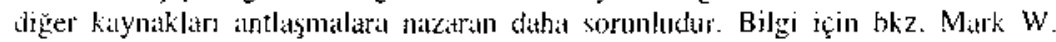
JANIS: An Introduction to Internationit Law. Second cd. Little. Brown and Co. [993. s. I0. 11. Antlaşmalar hukuku ile ilgili geniş hilgi için bkz. Id... s. 9-39: Malcolm N. SHAW: International Litw, Fourth ed. Cambridge University Press. I997. s. 632-773; Oscar SCHACHTER: International Law in Theory and Practice. Mariirus Nijhoff Publishers, 1991, s, 74-81; Louis HENKIN \& Richard Crawtord PUGH \& Oscar SCHACHTER \& Hans SMIT: International Law: Calses and Malterials. Second ed., St. Patul, Minn.: West Publishing Co., 1987. s. 69-88; Hüseyin PAZARCI: Ulusiararası Hukuk Dersleri. J. Kitıp. Gözden geçirilmiş 8. baskı. Ankilla: Turhan Kitabevi, 1999, s. 103-207.

5. Devletler bukukunun işleyişinde. iç hukuk sistemlerinin aksine, kuralların olış̧umu.

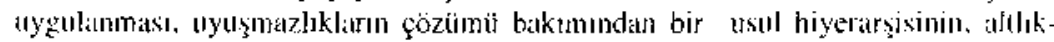

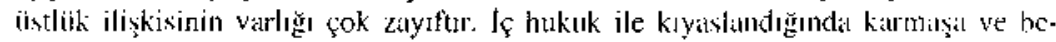
lifsizlik anlitmuna gelebilecek bu olgunun varlığna ragmen, nasil olup da, bu hukuk

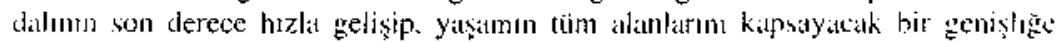
ulamasındaki baţarjnm ardında yation nedene gelince: verilecek sevatp temelde nokca altunda toplanabilir: I) Farklı devietlerin kendi alusal huk tk sistemlerinde ben.

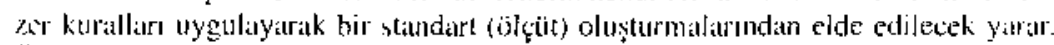

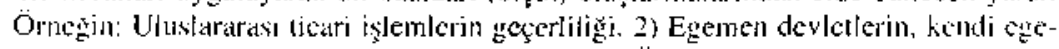

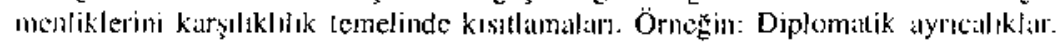
3) Devletlerin, ortak uluslararası hedeflere vitrmada Devletler hukuklinu tak

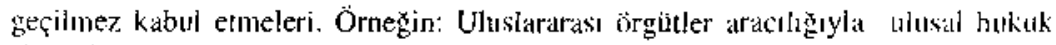

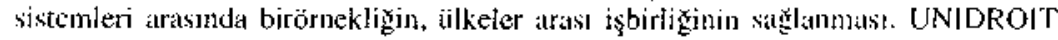
hiinyesinde çeşilli alanlarda birörnekleştirmeye yönelik olarık kabul eđ̛lilen sö\%-

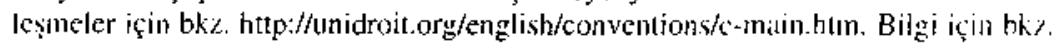
JANIS, op.cil., s. 8. 
datth huturmak, uluslararıss hukuk ilişkilerinde ve ulusial diijrenlemelede. kapsam içeriği belli bir terminokjiclen oluşan onlak bir dil kunuşnak bu amacm diĕer yansomalarrulır.

Uluskararası antlaşmayı onaylayan bir devletin. bütün bu söy-

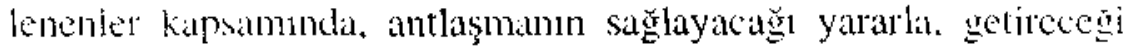
yükïmbïliikleri son derece dikkatle de ğerlendirip dengeleclĭ̌ni varsaymik gerektiğine şüphe yoktur. Antlaşmann onaylanmaisndan sonra attlacak adım ise, doğal olarak taraf olunan anthaşma is hukukun hangi alanına ilişkin ise, anţaşma gercklerinin ilgili mov/abion jçine yedirilmesi, ulusal mevzuatın uluslattaras antlaşna ile uyumlaştorlması olacaktur. Bu aşamanın gereklitiğ ve

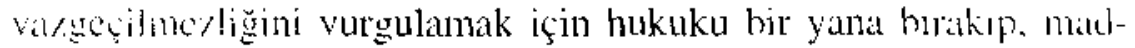
denin tubiatma bakmak bile yeterli olacaktsr. Eger bir dever bir

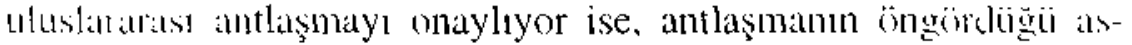

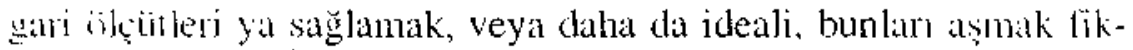
rincte demektir. Âkit devlet, ulusal hukukunun antlaşma kınusuna ilişkin bölümünde yapacağ iyileştirme ve uyumlaş̧ırma firalijedkriyle hem kendi hukukunun ve buna bağla olarak uy-

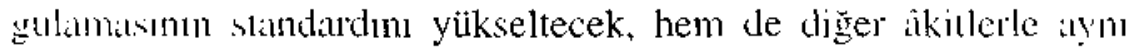
dili konussur, ontak yarara ve bu yolla kendi yararma hizmet eder duruma gelecektir.

Allmilsi gereken bu adımlarm herhangi birindeki eksiklik. lara! derleti uluslararası bukuk alanunda olduğu kadar. ulusal hukukundi dat içinden çıkılmaz sorunlara sürïkleyecektir. Ulus-

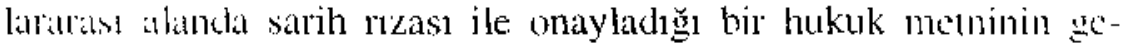
reklerini yerine getirmediği için antlaşmada öngörülen yaptırm yollarma mairuz kalan, en hafifinden taahhüdünuin gereklerini yerine setirnemeden doğan bil prestij kaybına uğrayan devleı, iç hu-

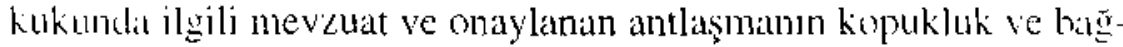

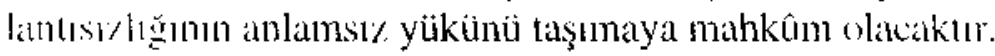

Türk uygulaması ise. yukarnda ifade edilen bu noktalian ne yaık ki haklı çıkaracak örneklerle doludur. Antlaşmaldatun onaylanmisma iliz̧kin usulde, Anayasaya uygunluk açısmdan bir ändenetim mekanizmasndan yoksun olan işleyişs, sonraki aşamalarda 
da, Batkanlar Kuruluna tannan denetimsiz geniş takdir yetkisi çerçevesinde $^{n}$, yasama ve yürütmeden oluşan ikili veya sadece yüriitme eliyle gerçekleşen onay safhalarıyla tamamlanmakta, 90. maddenin karmaşı Iafzı dahilinde, 90/III fikrasına dahil edilen antlaşmalar ise. Resmi Gazetede yayın ve TBMM bilgisine summa gereği olmaksızın kanun niteliği kazanmaktadır. Sağliklt bir degerlendirme ve denetim mekanizmasından yoksun olarak onaylanıp Türkiye Cumhuriyetini hem uluslararası hukuk anlamunda ba ğlayan. hem de iç hukukumuz bakımından kanun niteliğini kazanan antlaşmalar, yer aldıklan onay metinlerinin ekinde, sistematik bir yerleştimeden mahrum, unutulmaya terkedilmektedix.

Bugün hukuk sistemimizdeki görünüm. Türk iç hukuku ile taraf olunan antlaşmalarm biribirinden kopuk. uyumsuz ikj ayr yapı oluşturduğu*, ancak kamuoyunun ilgisini çekecek biçimde

6. Bugian de yürürlükte olan ve Anayasal sistemin ayrmulandırlimasına ilişkin olatak

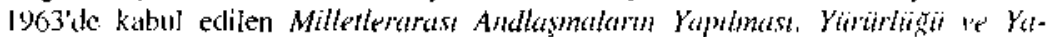

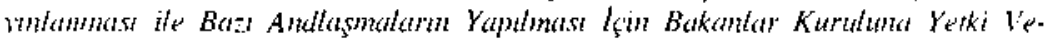
ritmesi Hakkmda 244 Sayth Kamun, getirdigi dizenleme ile Bakanlar Kurulumil.

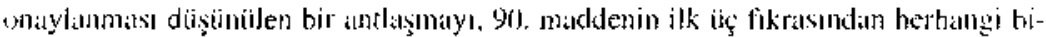
rine dahıl ederek ilgili fıkra usulünün işletilmesi yönünde genjş bir hareket imk ân titmumiktiadır.

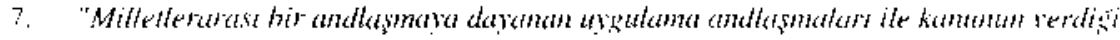

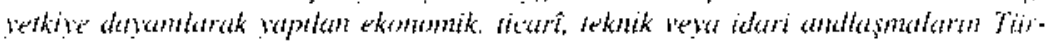

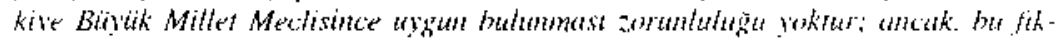

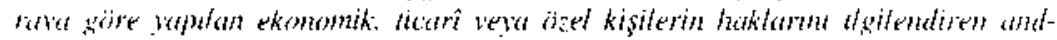

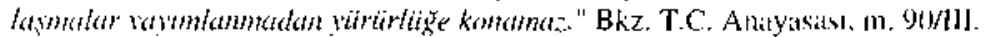

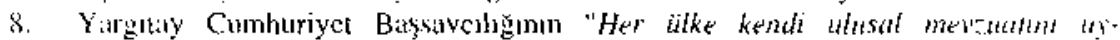

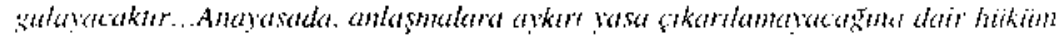

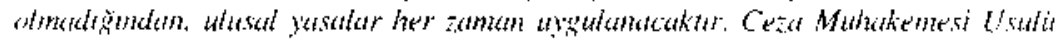

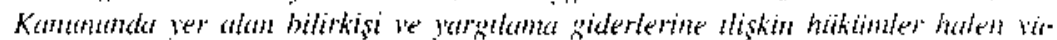

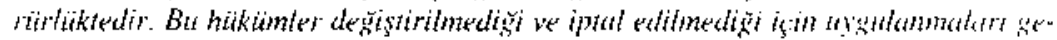

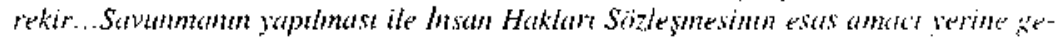

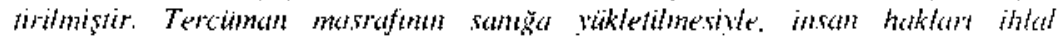
edilmemistir..." ifadeleriyle, yerel mahkeme häikmünïn onanmatsm talep elligi dilvada, Yargilay Ceza Genel Kurulunun. Avrupa Insan Hakları Sözleșmesinin "Her

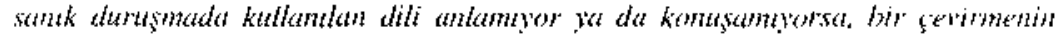
yardinmdan äcretsiz olarak yorarlanmak hakkma sahipht." hükmiinä esits alarak

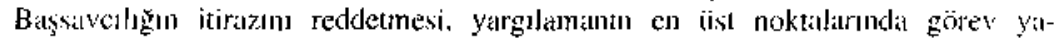
pambarm bile, kamuniarlat, onaylanarak kanun niteliğini kazanan anllaşmalan birbirinden kopuk iki ayrı dïzenleme olarak algladıklarmn göstermektedir. Yarguly Cc\%a zencl Kurulunun E. 1996/6-2; K. 1996/33 Katrarr içia bkz. Aslın GÜNDUiz: 
gämulenc gelen insan haklari" veya ILO sözlesmeleri" hen/eri ki-

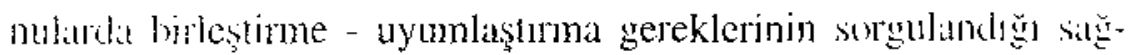
liksw. bit manzara ar\%emektedir. Tarat olduğu uluslatamsi memi.

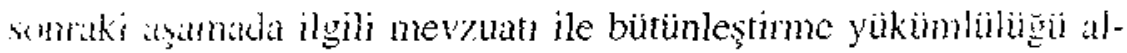

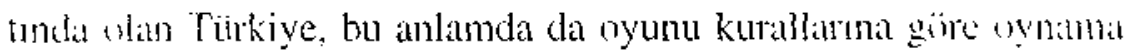
açisindatn yetersio kalmaktadu.

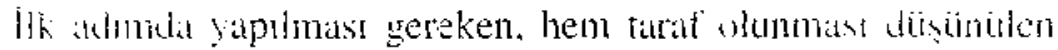

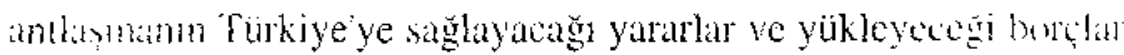
hakmman saglikh bir sekilde ahliline olamak verecek. hem th ike-

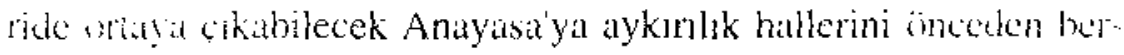

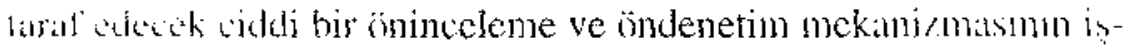
letihus whak görümmektedir Böyle bir denetimin yokluğma. Analyal Mahkemesinin 416,3 sayld "slam Ulkeleri Arast Kammi

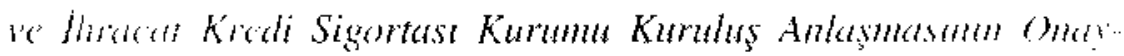

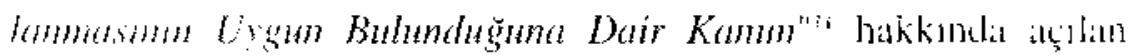

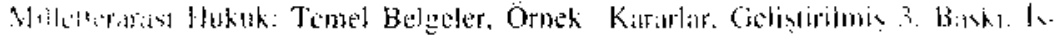

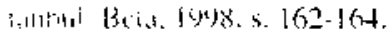

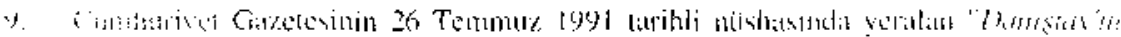

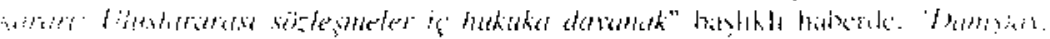

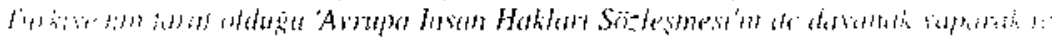

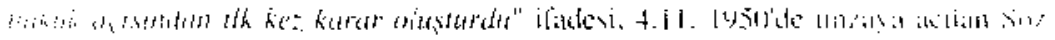

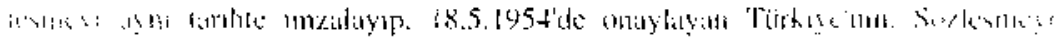

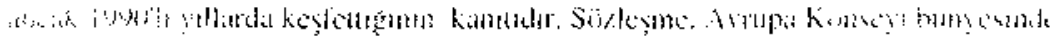

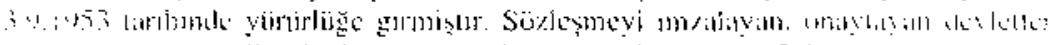

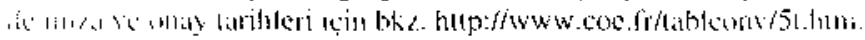

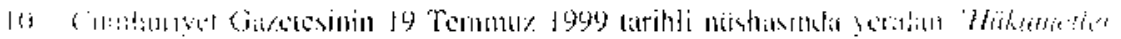

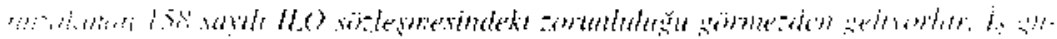

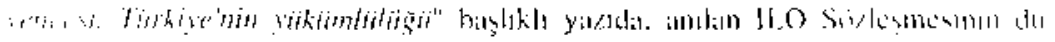

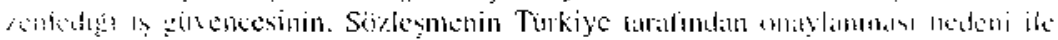

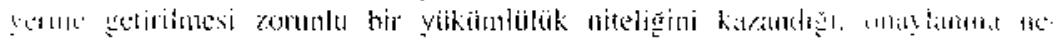

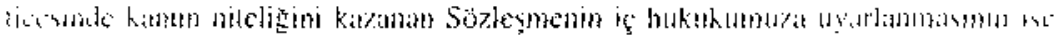

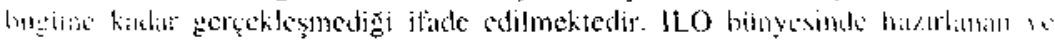

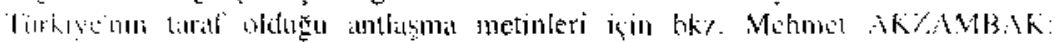

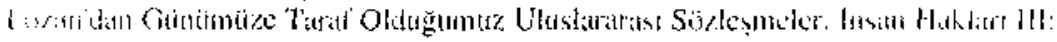

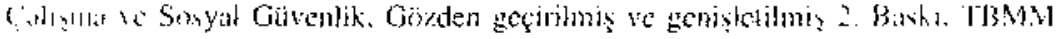
Kultu. Sallill ve Yaym Kurulu Yaymlars No: 80. Ankillit. 1908.

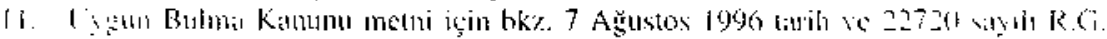

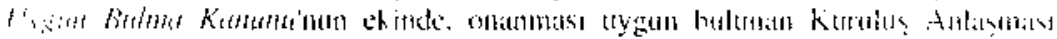

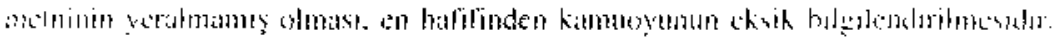


iplal davasmda, "ulaslararasi anlaşmalarm onay/anmasma dair vasalarm Anavasa Mahkemesi denetimine tâhi oldoğuna" dair "yybirliğ ile aldı̆̆ 1 karar $^{-12}$, sistemin böyle tehlikeli bir boşluğg kendi işleyişi içinde doldurmaya çalıştığımn göoster'gesidir ${ }^{\prime:}$.

Her ne kadar, usulüne uygun olarak yürürlüge giren ulusJaratasi antlaşmalar Anayasamı uyarınca kanun niteliğini kitranınakta ise de, antlaşmanın, ancak çok somu düzenlemeler getimesi halinde, kendisi ile çatışr nitelikte hükümler jçeren eski tarihli kanumu zımnen değiştirdiği neticesine nispeten kolaylıklat varnlabilir. Buna karşllık, somut dizenlemeler getirmek yerine bazı ilkelerj belirleyen bir uluslararası antlaşmanın, usulüne uygun olarak onaylanp kanun niteliğini kazanması, herkes tarafindan lajlişması anlaşlip uygulanabilmesi sonucunu doğurmayabilir. Böyle bir durumda, gerek yürütme, gerek yargl organlarmaki uygulayıcılar, düzenlemekte olduğu alana ilişkin ilkeler getiren yeni tarihli uluslararası antlaşma ile, o ilkelere ters kurallar içeren eski larihli kanın çıkmazında sıkışıp kalacaklaudır.

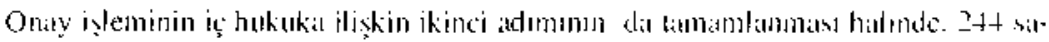

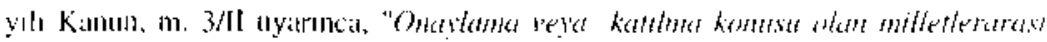

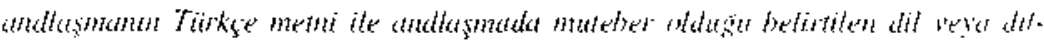

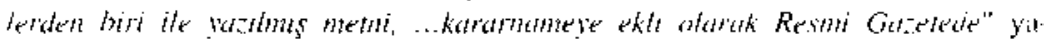
ymianacak ofmakla hirlikte. uygun bulma kauduns ekinde antlaşma melninin ye-

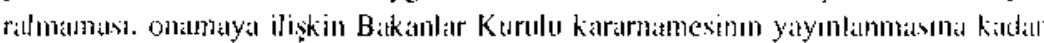

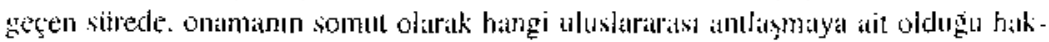
kında kämuoyunu karanlıkta burakınak aniammil geimektcolir.

12. Bks. Kamu Hizmetinde Özelleștirme. KlGEM. Ankitrit. 1997. s. 18. dipnot 25

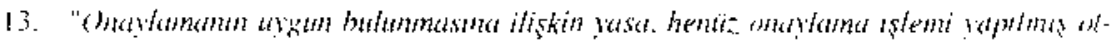

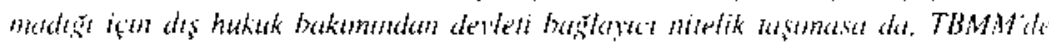

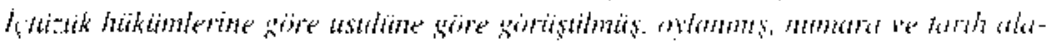

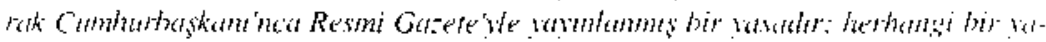

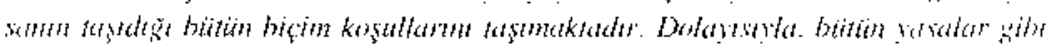

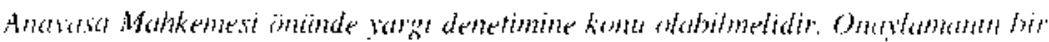

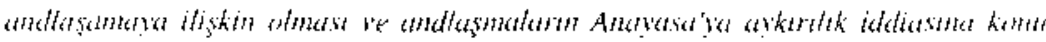

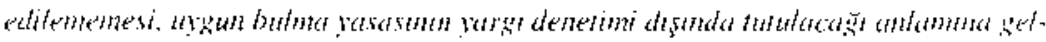
me-" Bk/. SOYSAL. on cit. s. 178. 


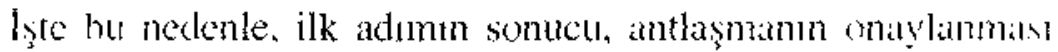
şeklincle somurlaşur ise, ilgili mevauatn. onaylanarak kanun ni-

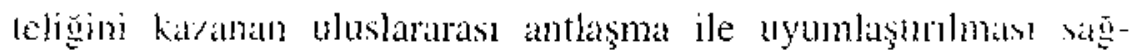
fanmaludn. Ancak bu yolla bir bütünlük arzedecek olan ulusal merstat. jlişkiferin diizenlenmesinde, uyuşmazlıklatın çö̌zümiemmesinde tek hir yapr olarak ayguknabilit. Yine bu sayede. ulastararasi hukuk bakımından yaşanacak sorunlar aş̧larak, bir antlaşmaya laral olmamm hem iç hukuk, hem uluslararası hukık bakmmllan dogruacatag yarar ve dengelere ulaşılls. 